\title{
The prediction of intraoperative cervical cord function changes by different motor evoked potentials phenotypes in cervical myelopathy patients
}

Shujie Wang ${ }^{1 \dagger}$, Zhifu Ren ${ }^{2 \dagger}$, Jia Liư ${ }^{3}$, Jianguo Zhang ${ }^{1}$ and Ye Tian ${ }^{1 *}$

\begin{abstract}
Background: Surgery is usually the treatment of choice for patients with cervical compressive myelopathy (CCM). Motor evoked potential (MEP) has proved to be helpful tool in evaluating intraoperative cervical spinal cord function change of those patients. This study aims to describe and evaluate different MEP baseline phenotypes for predicting MEP changes during CCM surgery.

Methods: A total of 105 consecutive CCM patients underwent posterior cervical spine decompression were prospectively collected between December 2012 and November 2016. All intraoperative MEP baselines recorded before spinal cord decompression were classified into 5 types (I to $V$ ) that were carefully designed according to the different MEP parameters. The postoperative neurologic status of each patient was assessed immediately after surgery.

Results: The mean intraoperative MEP changes range were $10.2 \% \pm 5.8,14.7 \% \pm 9.2,54.8 \% \pm 31.9,74.1 \% \pm 24.3$, and $110 \% \pm 40$ in Type I, II, III, IV, and V, respectively. There was a significant correlation of the intraoperative MEP change rate with different MEP baseline phenotypes $(r=0.84, P<0.01)$. Postoperative transient new spinal deficits were found 0/31 case in Type I, 0/21 in Type II, 1/14 in Type III, 2/24 in Type IV, and 4/15 in Type V. No permanent neurological injury was found in our cases series.
\end{abstract}

Conclusions: The MEP baselines categories for predicting intraoperative cervical cord function change is proposed through this work. The more serious the MEP baseline abnormality, the higher the probability of intraoperative MEP changes, which is beneficial to early warning for the cervical cord injury.

Keywords: Cervical compressive myelopathy (CCM), Motor evoked potential (MEP), Intraoperative neuromonitoring, MEP baselines phenotypes, Intraoperative cervical cord function changes

\footnotetext{
*Correspondence: pumchtianye@163.com; wsj_8059@126.com

'Shujie Wang and Zhifu Ren contributed equally to this work.

'Department of Orthopedics, Peking Union Medical College Hospital,

Chinese Academy of Medical Sciences \& Peking Union Medical College, 1

Shuai Fu Yuan, Beijing 100730, PR China

Full list of author information is available at the end of the article
}

(C) The Author(s). 2020 Open Access This article is licensed under a Creative Commons Attribution 4.0 International License, which permits use, sharing, adaptation, distribution and reproduction in any medium or format, as long as you give appropriate credit to the original author(s) and the source, provide a link to the Creative Commons licence, and indicate if changes were made. The images or other third party material in this article are included in the article's Creative Commons licence, unless indicated otherwise in a credit line to the material. If material is not included in the article's Creative Commons licence and your intended use is not permitted by statutory regulation or exceeds the permitted use, you will need to obtain permission directly from the copyright holder. To view a copy of this licence, visit http://creativecommons.org/licenses/by/4.0/ The Creative Commons Public Domain Dedication waiver (http://creativecommons.org/publicdomain/zero/1.0/) applies to the data made available in this article, unless otherwise stated in a credit line to the data. 


\section{Background}

Cervical compressive myelopathy (CCM) is one of the most commonly acquired cause of spinal cord dysfunction [1], and surgery is usually the treatment of choice for those patients. It is important to assess cervical cord function in patients with CCM during surgical treatment. Over the past decades, the majority of studies are concerning the application of intraoperative transcranial motor evoked potential (MEP) to detect impending spinal cord damage, early warning the operating team to take action to avoid injury in cervical spine surgery [2-7].

Previously, imaging methods such as magnetic resonance imaging (MRI) are able to detect pathologic changes in patients with CCM, and are thought to be useful for the evaluation of prognosis [8-12]. Another reported predictor of postoperative prognosis is the preoperative cross-sectional area of the spinal cord at the site of maximum compression [13-15]. furthermore, somatosensory-evoked potentials (SEPs) classification system could be used as an objective tool, in addition to clinical scales, for the quantitative assessment of spinal cord function in CCM [16]. These are preoperative prediction methods for postoperative spinal cord function change.

Currently, we have found that the different intraoperative MEP baselines before cord decompression probably can predict the impending neuromonitoring changes after spinal canal decompression. In order to further test this hypothesis, our objective was to put forward different intraoperative MEP phenotypes and verify its feasibility for predicting the neuromonitoring changes after spinal decompression in CCM patients.

\section{Methods}

\section{Patients}

We prospectively collected 105 consecutive patients from December 2012 to December 2016. The major clinical characteristics and diagnosis of the population were showed in Table 1. Patients were eligible for this study when they met all the following inclusion criteria: (1) presenting with symptomatic CCM with at least 1 clinical sign of myelopathy; (2) evidence of objective CCM on a magnetic resonance image (MRI); (3) absence symptomatic lumbar stenosis or thoracic myelopathy; (4) no previous surgical treatment for CCM; (5) undergoing the same anesthesia regime. Patients' duration of symptoms and preop modified Japanese Orthopedic Association (mJOA) scores associated with MEP phenotypes were showed in Fig. 1.

Preoperative and postoperative neurological assessment All patients underwent a detailed preoperative assessment of neurological function and the degree of cord
Table 1 The general data and the clinical diagnoses of all patients

\begin{tabular}{ll}
\hline General data and diagnosis & Mean \pm SD (Range)/N (\%) \\
\hline General data & $58.2 \pm 11.1(26-75 \mathrm{y})$ \\
Age & $71 / 34$ \\
Male/Female & $168.9 \pm 8.4(140-180 \mathrm{~cm})$ \\
Height & $71.4 \pm 14.1(42-98 \mathrm{~kg})$ \\
Weight & $24.9 \pm 4.1(15-34)$ \\
BMl & $164.8 \pm 39.3(110-300 \mathrm{~min})$ \\
Operation time & $232.2 \pm 179.5(150-900 \mathrm{ml})$ \\
Bleeding volume & \\
Diagnosis (n, \%) & $63(60.0 \%)$ \\
Cervical spondylotic myelopathy & $13(12.4 \%)$ \\
OPLL & $6(5.7 \%)$ \\
Cervical disk herniation & $4(3.8 \%)$ \\
Congenital anomaly of cervical spine & $12(11.4 \%)$ \\
Atlantoaxial subluxation & $7(6.7 \%)$ \\
Others & \\
Type of surgery (n, \%) & $19(18.1 \%)$ \\
ACDF & $78(74.3 \%)$ \\
PCDF & $8(7.6 \%)$ \\
Laminectomy &
\end{tabular}

OPLL Ossification of posterior longitudinal ligament, ACDF Anterior cervical decompression and fusion, PCDF Posterior cervical decompression and fusion

compression on MRI with MEP baseline recording. The postoperative neurologic status of each patient was assessed immediately after surgery by comparing the patient's documented preoperative motor and sensory function with his or her early postoperative motor and sensory function.

\section{Intraoperative electrophysiological assessment}

Two kinds of monitoring instruments (Cadwell Industries Inc. Cascade Pro Systems, Kennewick, WA, USA; Axon Systems Inc., Hauppauge, NY) were used. Moreover, MEP testing was performed after showing the vertebral lamina using subcutaneous needle electrodes by stimulating of $400 \mathrm{~V}$ constant voltage and multiple trains of 6 pulses, with duration of $400 \mu \mathrm{s}$. The inter-stimulus interval was $2.5 \mathrm{~ms}$ for each stimulation trains. The two pairs of stimulation electrodes were inserted subcutaneously over motor cortex regions $\mathrm{C} 3-\mathrm{C} 4$. Recording electrodes were placed into the abductor hallucis muscles in both of the lower extremities and the first dorsal interosseous muscles in the upper extremities (control).

According to many previous studies [17] and our experience [18-21], in cervical compressive myelopathy (CCM) patients underwent neural decompressive surgery, the surgical induced MEP alerting often derived from the procedure of spinal decompression especially 


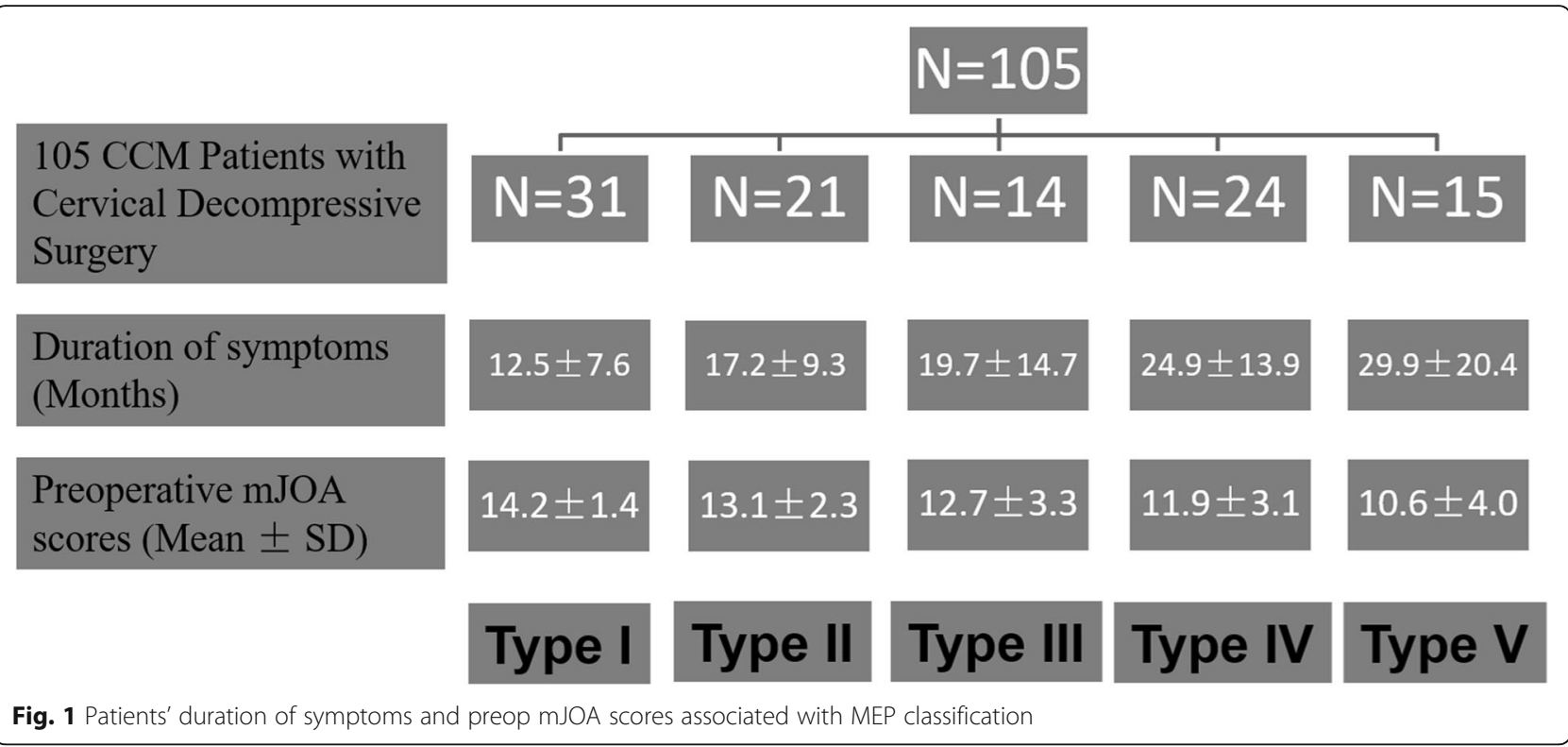

severe spinal oppression segment. Otherwise it is often physiological or false-positive and we should first rule out systemic and anesthetic factors first [22]. The MEPs could be read directly from our monitoring instrument in every surgical point and were collected by averaging three times.

\section{The 5 MEP types}

In current study, a different MEP phenotype (Table 2) was firstly addressed for predicting the IONM changes for CCM patients e.g. in Fig. 2.

Type I indicated safe MEP baseline with excellent stability;

Type II also indicated safe MEP baseline with good stability;

Type III was referred to sensitive MEP baseline with average stability;

Type IV was high-sensitive MEP with poor stability;

Type $\mathrm{V}$ was indeterminate/high risk MEP baseline.

The MEPs were recorded from the foot muscles (abductor hallucis) for the classification. The MEP types in this study aimed at unilateral baseline, amplitude and latency were considered as peak to peak and the initial of

Table 2 The detail of different MEP baseline phenotypes

\begin{tabular}{llll}
\hline Types & Amplitude $(\mu \mathrm{V})$ & Latency $(\mathrm{ms})$ & Stability \\
\hline I & $>300$ & $<50$ & Excellent \\
II & $>300$ & $>50$ & Good \\
& $100-300$ & $<50$ & \\
III & $100-300$ & $>50$ & Moderate \\
IV & $20-100$ & - & Poor \\
V & $0-20$ & - & Indeterminate/High Risk \\
\multicolumn{7}{l}{ The MEP types in this study aimed at unilateral baseline }
\end{tabular}

trains' stimulation to the initial of MEP response respectively. And the baseline classification in Table 2 relies on the MEP stability that is defined based on the amplitude and latency.

\section{Anesthesia management}

General anesthesia was induced with a bolus dose of propofol $(3 \mathrm{mg} / \mathrm{kg})$ and fentanyl $(2.5 \mu \mathrm{g} / \mathrm{kg})$ combined with a short-acting muscle relaxant (rocuronium) and inhalation agents (sevoflurane or nitrous oxide). Subsequently, maintenance of anesthesia was propofol (5-8 $\mathrm{mg} / \mathrm{kg} / \mathrm{h}$ ) based on hemodynamic response; remifentanyl $(0.05-2 \mu \mathrm{g} / \mathrm{kg} / \mathrm{min})$; and a total dose of $5-6 \mu \mathrm{g} / \mathrm{kg}$ fentanyls (intermittent infusion) were used. No muscle relaxant or inhalation agent was used after anesthesia induction.

It should be noted that anesthetic is crucial role for MEP recording and classification, so all consecutive patients underwent the same anesthesia regime. MEP baseline must be recorded after performing the rocuronium of more than $50 \mathrm{~min}$ [23]. The patients with different TOF might affect the MEP responses, even using total intravenous anesthesia (TIVA), thus within $100 \pm 5 \%$ TOF changes were confirmed when recording MEP baseline (Fig. 3). Moreover, the electroencephalographic density spectral array was also used to evaluate the depth of anesthesia, and we also strictly controlled the BIS value as 50-60 when recording the MEP signals.

\section{Statistical analysis}

General data of patients were described as means and $\mathrm{SD}$ or $\mathrm{n}(\%)$, and the statistical analyses were performed using Microsoft Excel 2007 (Microsoft, Redmond, WA, USA) and SPSS 19.0 (SPSS, Inc., Chicago, IL, USA) 


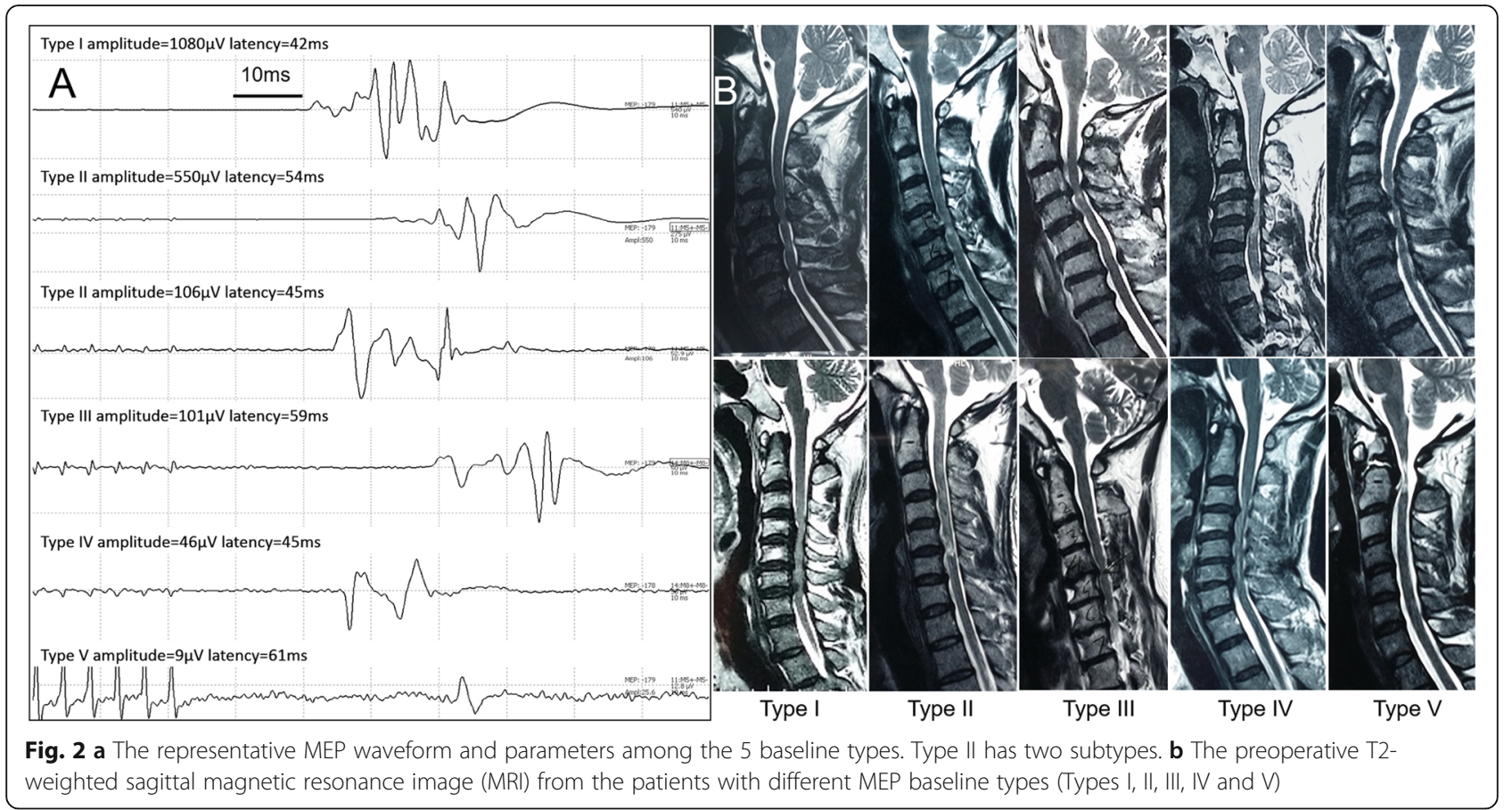

software. Statistical comparisons were made by $x^{2}$ test, and $P<0.05$ was considered significant. Pearson's correlation test was applied to evaluate the correlation of MEP phenotypes with the incidence of intraoperative monitoring changes.

\section{Results}

Our results showed that 31 cases were classified as type I, 21 as type II, 14 as type III, 24 cases as type IV, and 15 cases as type $\mathrm{V}$. The mean MEP changes range were $10.2 \% \pm 5.8,14.7 \% \pm 9.2,54.8 \% \pm 31.9,74.1 \% \pm 24.3$, and $110 \% \pm 40$ in Type I, II, III, IV, and V, respectively. With the MEP types proceeding, the neuromonitoring changes is increasing. And there was a significant correlation of the intraoperative MEP change rate with different MEP baseline classification $(r=0.84, P<0.01)$ (Fig. 4).

No significant neuromonitoring change and postoperative new spinal deficit was found in Type I \& II. Among 14 patients in Type III, 2 showed significant MEP losses, 5 showed intraoperative MEP improvements. Among 24 patients in Type IV, 4 showed significant MEP loss, 6 showed MEP improvements. Among 15 patients in Type V, 7 showed significant MEP loss, 6 showed MEP improvements (Table 3). Postoperative new spinal deficits

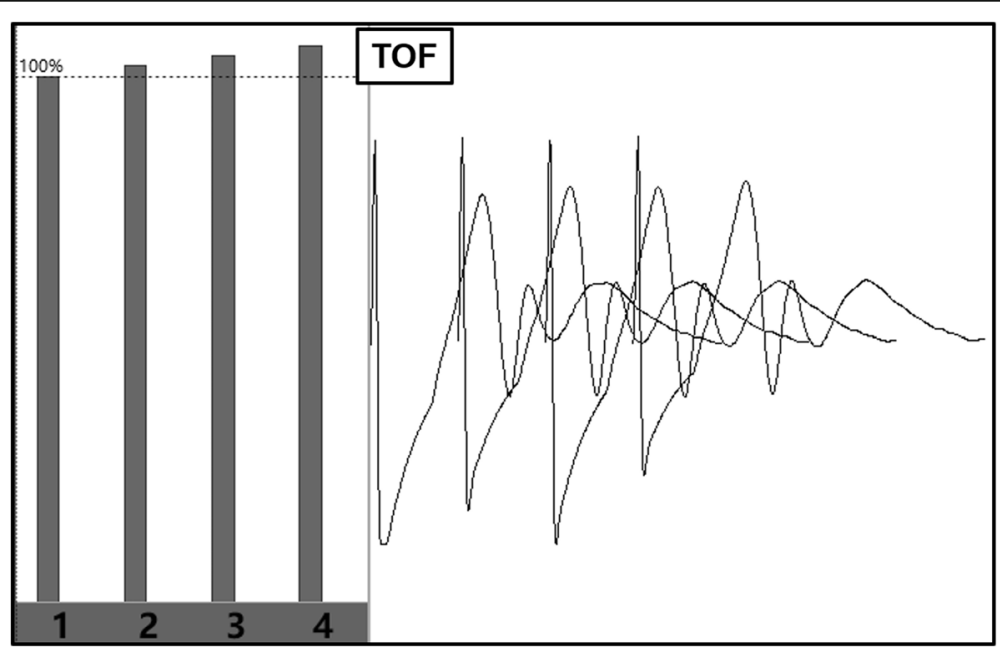

Fig. 3 The TOF were monitored when recording MEP baseline 


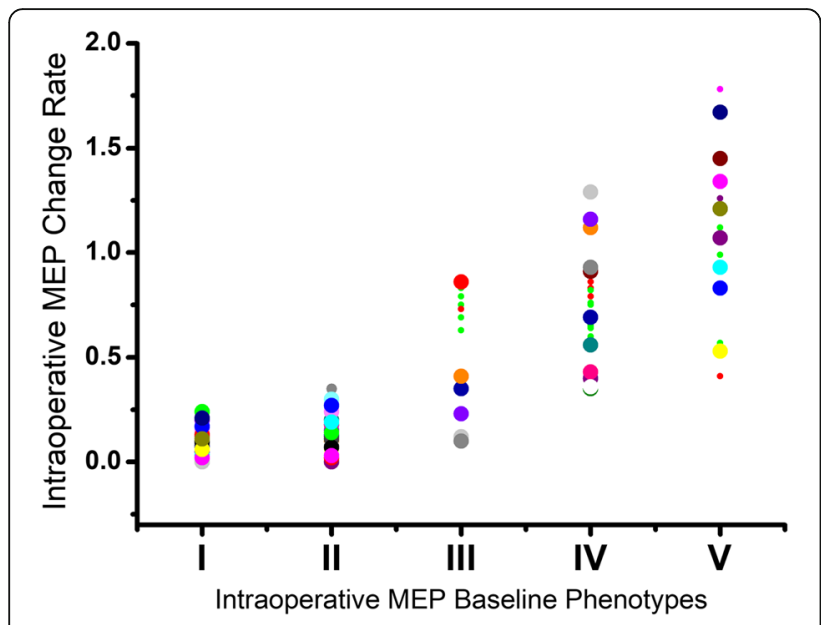

Fig. 4 Absolute value distribution of intraoperative MEP change rate with different baseline phenotypes

were found 0/31 case in Type I, 0/21 in Type II, 1/14 in Type III, 2/24 in Type IV, and 4/15 in Type V. Furthermore, Multivariate analysis indicated that these three variables (Duration of symptoms, Preoperative SC crosssectional area, MEP baseline categories) were also the main significant contributors for the impending MEP warning. (Table 4).

\section{Discussion}

The present study had focused on describing different MEP phenotypes for predicting intraoperative neuromonitoring change in patient underwent cervical cord decompression surgery. The main finding of this study was that the MEP baselines were classified into 5 types to imply the possibility of monitoring changes in different level during CCM surgery. The type I and II are safe and stable MEP baseline that generally does not present significant intraoperative monitoring changes; type III and IV are sensitive MEP baseline that should attract our attention for possible monitoring changes; type $\mathrm{V}$ is highrisk MEP baseline that would imply a possibility of great neuromonitoring changes. The main clinical significance of this knowledge was that we provide a novel predictor to help surgeons further assess the possible changes of cervical cord function, identify high-risk patients and then institute rigorous prevention strategies to achieve safer and more secure treatment for CCM patients.
Table 4 Results of stepwise multivariate regression analysis

\begin{tabular}{lll}
\hline Variable $=\boldsymbol{\beta}_{\boldsymbol{0}}$ & \multicolumn{2}{l}{ MEP warning } \\
\cline { 2 - 3 } & \multicolumn{2}{l}{ Model: $\left(\mathrm{R}^{2=} 0.301, p<0.01\right)$} \\
\cline { 2 - 3 }$\beta$-coefficient & $P$ Value \\
\hline Duration of symptoms & 0.205 & 0.0081 \\
Preoperative mJOA score & 0.018 & 0.0358 \\
Preoperative SC cross-sectional area & 0.189 & 0.0095 \\
MEP baseline categories & 0.268 & 0.0026 \\
\hline
\end{tabular}

Note: All independent variables were entered into the regression. Values denoted are $\beta$-coefficient values (95\% confidence intervals)

mJOA Japanese Orthopedic Association, MEP Motor-Evoked Potentials, SC Spinal Cord

The rationale for MEP monitoring is to directly test the integrity of lateral corticospinal tract and cervical nerve roots and then assess the function of motor system during cervical spine surgery [24, 25]. And MEPs amplitude change is highly sensitivity (approaching $100 \%$ \& specificity (more than $95 \%$ ) $[22,26,27]$ ) to predict a new postoperative neurological injury. Thus, MEP baseline signal may indicate the impairment's degree of cervical cord or motor system dysfunction in pure CCM patients. During the patients with the type I or II MEP baseline, the injuries degree of nervous tissue from blood supply or direct mechanical cord compression are probably in relative compensatory stage.

On the other hand, the accumulated experimental evidence suggests that reperfusion lesions can result in neuronal death, which reactive oxygen radicals have been implicated to play an important role after decompression of a chronic compressive lesion of the cervical cord [28-30]. And reperfusion can occur in any level and any spot where surgical decompression was performed for the chronic compressive lesion. The severity and area of the reperfusion lesions depend on the area where neurons are really damaged. Theoretically, the neurons from cervical cord cannot present the high-risk reperfusion lesions in those patients with type I and II MEPs baseline. Meanwhile our current data can also support this point. The 52 patients with type I and II MEPs baseline did not appear significant intraoperative monitoring loss or new spinal deficit. Therefore, the type I and II MEPs baseline is safe and will usually not show an impending significant monitoring loss and then to predict cervical cord injury during the surgery of CCM.

Table 3 The summary of monitoring changes and new neurologic deficit for each MEP baseline type from 105 CCM patients

\begin{tabular}{|c|c|c|c|c|c|}
\hline & Type I & Type II & Type III & Type IV & Type V \\
\hline Significant monitoring loss & 0 & 0 & 2 & 4 & 7 \\
\hline Significant monitoring improvement & 0 & 1 & 5 & 6 & 6 \\
\hline New neurologic deficits & 0 & 0 & 1 & 2 & 4 \\
\hline Total cases (\%) & 31 (29.5\%) & $21(20.0 \%)$ & $14(13.3 \%)$ & 24 (22.9\%) & $15(14.3 \%)$ \\
\hline
\end{tabular}


Next, the CCM patients with Type III and IV MEPs baseline often have severe and long-term preoperative cervical cord compression and then perform poor MEP baselines. According to our data and experience, the monitoring signals often change in the patients with these baseline types. Interestingly, the patients with Type III or IV baseline not only perform a monitoring loss but also lots of monitoring improvement cases (Table 3). In our opinion, the mainly reason for monitoring loss is probably related to neural reperfusion lesions injury; the monitoring improvement is probably because the excitability of neuron or corticospinal tract is improving following cervical cord decompression. And the increasing arterial supply would also improve spinal cord ischemia and then benefit the MEP augment. Moreover, many previous studies have also proved that in patients with preoperative compression of the spinal cord or cauda equina, resulting in low or absent monitoring at the start of surgery, an immediate increase in MEPs after surgical decompression may predict a recovery of neurologic outcomes [31-34]. Furthermore, during our finding, only when the MEP baseline was in the Type III or IV, the amplitude would change easily and frequently and we should be careful that ahead of the cord decompression. Thus, the MEP in Type III or IV is high-sensitive baseline that should really be aroused our attention.

The Type $\mathrm{V}$ often derives from the patients with preoperative severe cervical cord compression, which often present sporadic disappearance or sudden enlargement without high-risk surgical maneuvers. On the basis of previous study, [35-38] increasing degrees of spinal cord deficits were associated with depressed feasibility of intraoperative MEP/SEP monitoring, respectively. Moreover, according to our data and experience, the Type $\mathrm{V}$ MEP baseline is really very difficult to accurately predict a new neurologic deficit, but when it is constant or amplifying after cervical cord decompression that usually implies a favorable prognostic in CCM patients.

MEPs reflect spinal cord functional status, especially pathologic changes in the entire corticospinal motor system below the brain stem [39-45]. The type III, IV, and V MEPs baseline can often gradually reflect the severity of clinical symptoms. Some previous study also showed a correlation between the mJOA score and the electrophysiological parameters in CCM [7, 18, 19, 46]. Moreover, according to this study and previous report [47], the cervical cord morphology and electrophysiological parameters are also relevant in CCM. Therefore, we can draw the conclusion that there are significant correlations among cervical cord morphology, electrophysiological parameters and clinical features. As thus we can use the MEP classification to represent the quantitative neurologic function and provide the high-sensitive MEP types to help us to predict the monitoring change ahead in decompressive CCM surgery.

\section{Limitations}

There are some limitations must be clarified in this study. First, the MEP baseline classification is derived from our hypothesis and experience of a single institution. Further studies enrolling larger number of cases and a multicenter prospective evaluation of the reliability and validity of this new classification are needed. Second, although we believe our analysis to be compelling, the new classification system is still in the stage of exploration and appropriate corrections are much needed in the future. Third, because of the number of patients in this study was relatively small, the postoperative new spinal deficit among the 5 types did not present statistical significance (Table 3). But the correlations between the MEP baseline and the postoperative spinal deficit are appearing in our follow-up study of large sample cases.

\section{Conclusions}

In this paper, we exhibited different MEP phenotypes before surgical spinal decompression during CCM patients. Using this MEP classification, the more serious the MEP baseline abnormality, the higher the probability of intraoperative monitoring changes. That is probably help surgeons to predict the impending spinal cord function changes in CCM patients.

\section{Abbreviations \\ CCM: Cervical Compressive Myelopathy; MEP: Motor Evoked Potential; mJOA: Modified Japanese Orthopedic Association; TIVA: Total Intravenous Anesthesia}

\section{Acknowledgements}

Not applicable.

\section{Authors' contributions}

WSJ performed the intraoperative electrophysiological recording, collected the clinical data and wrote this manuscript. RZF\&LJ revised the manuscript and collected the medical records. ZJG edited the article for proper English language and followed up this case. TY conceived and designed this study and completed the whole manuscript revision work. All authors discussed the results and approved the final version.

\section{Funding}

There is no funding related to this article.

\section{Availability of data and materials}

All data generated or analyzed during this study are included in this published article.

\section{Ethics approval and consent to participate}

All the patients included in this study provided written informed consent in accordance with the principles of the Declaration of Helsinki and the study was approved by Peking Union Medical College Hospital Ethics Committee. And all methods were carried out in accordance with relevant guidelines and regulations. 


\section{Consent for publication}

All the patients included in this study provided written informed consent for publication of this article and any accompanying images. A copy of the written consent is available for review by the Editor of this journal.

\section{Competing interests}

The work reported in the present manuscript was not supported financially and no conflicts of interest for any of the authors needs to be mentioned.

\section{Author details}

'Department of Orthopedics, Peking Union Medical College Hospital, Chinese Academy of Medical Sciences \& Peking Union Medical College, 1 Shuai Fu Yuan, Beijing 100730, PR China. ${ }^{2}$ Department of Spine Surgery, Municipal Traditional Chinese Hospital, Weifang, Shandong 261041, PR China. ${ }^{3}$ China-America Institute of Neuroscience, Xuanwu Hospital, Capital Medical University, Beijing 100053, China.

Received: 5 December 2019 Accepted: 19 May 2020

Published online: 30 May 2020

\section{References}

1. Karpova A, et al. Predictors of surgical outcome in cervical spondylotic myelopathy. Spine (Phila Pa 1976). 2013;38(5):392-400.

2. Clark AJ, et al. Intraoperative neuromonitoring with MEPs and prediction of postoperative neurological deficits in patients undergoing surgery for cervical and cervicothoracic myelopathy. Neurosurg Focus. 2013;35(1):E7.

3. Hilibrand AS, et al. Comparison of transcranial electric motor and somatosensory evoked potential monitoring during cervical spine surgery. J Bone Joint Surg Am. 2004;86-A(6):1248-53.

4. Ukegawa D, et al. Efficacy of biphasic transcranial electric stimulation in intraoperative motor evoked potential monitoring for cervical compression myelopathy. Spine (Phila Pa 1976). 2014;39(3):E159-65.

5. Sakaki $\mathrm{K}$, et al. Warning thresholds on the basis of origin of amplitude changes in transcranial electrical motor-evoked potential monitoring for cervical compression myelopathy. Spine (Phila Pa 1976). 2012;37(15): E913-21.

6. Kim DH, et al. Risk factors for false positive transcranial motor evoked potential monitoring alerts during surgical treatment of cervical myelopathy. Spine (Phila Pa 1976). 2007;32(26):3041-6.

7. Nakanishi $\mathrm{K}$, et al. Electrophysiological evidence of functional improvement in the corticospinal tract after laminoplasty in patients with cervical compressive myelopathy: clinical article. J Neurosurg Spine. 2014;21(2):210-6

8. Uchida $\mathrm{K}$, et al. Prognostic value of changes in spinal cord signal intensity on magnetic resonance imaging in patients with cervical compressive myelopathy. Spine J. 2014;14(8):1601-10.

9. Nouri A, et al. Role of magnetic resonance imaging in predicting surgical outcome in patients with cervical spondylotic myelopathy. Spine (Phila Pa 1976). 2015:40(3):171-8.

10. Zhang JT, et al. Predictors of surgical outcome in cervical spondylotic myelopathy: focusing on the quantitative signal intensity. Eur Spine J. 2015; 24(12):2941-5.

11. Nouri $\mathrm{A}$, et al. Does magnetic resonance imaging improve the predictive performance of a validated clinical prediction rule developed to evaluate surgical outcome in patients with degenerative cervical myelopathy? Spine. 2015;40(14):1092-100.

12. Tetreault $L A$, et al. Systematic review of magnetic resonance imaging characteristics that affect treatment decision making and predict clinical outcome in patients with cervical Spondylotic myelopathy. Spine. 2013; 38(22):S89-S110

13. Okada $Y$, et al. Magnetic-resonance-imaging study on the results of surgery for cervical compression myelopathy. Spine. 1993;18(14):2024-9.

14. Wada $\mathrm{E}$, et al. Can intramedullary signal change on magnetic resonance imaging predict surgical outcome in cervical spondylotic myelopathy? Spine. 1999;24(5):455-61

15. Kanchiku T, et al. A correlation between magnetic resonance imaging and electrophysiological findings in cervical spondylotic myelopathy. Spine (Phila Pa 1976). 2001:26(13):E294-9.

16. Hu Y, et al. Prognostic value of somatosensory-evoked potentials in the surgical management of cervical spondylotic myelopathy. Spine (Phila Pa 1976). 2008;33(10):E305-10.
17. Yoshida G, et al. Alert timing and corresponding intervention with intraoperative spinal cord monitoring for high-risk spinal surgery. Spine (Phila Pa 1976). 2019;44(8):E470-9.

18. Wang S, et al. Prognostic value of intraoperative MEP signal improvement during surgical treatment of cervical compressive myelopathy. Eur Spine J. 2016;25(6):1875-80.

19. Wang S, Tian Y. Exploration of the intraoperative motor evoked potential. Spine (Phila Pa 1976). 2016:41(6):470-5.

20. Wang $S$, et al. Comparison of intraoperative neurophysiologic monitoring outcomes between cervical and thoracic spine surgery. Eur Spine J. 2017; 26(9):2404-9.

21. Wang SJ, et al. High-risk surgical maneuvers for impending true-positive intraoperative neurologic monitoring alerts: experience in 3139 consecutive spine surgeries. World Neurosurg. 2018;115:E738-47.

22. Wang $\mathrm{S}$, et al. Intraoperative motor evoked potential monitoring to patients with preoperative spinal deficits: judging its feasibility and analyzing the significance of rapid signal loss. Spine J. 2017:17(6):777-83.

23. Ishigaki S, Masui K, Kazama T. Saline Flush After Rocuronium Bolus Reduces Onset Time and Prolongs Duration of Effect: A Randomized Clinical Trial. Anesth Analg. 2016;122(3):706-11.

24. Macdonald DB, et al. Intraoperative motor evoked potential monitoring - a position statement by the American Society of Neurophysiological Monitoring. Clin Neurophysiol. 2013;124(12):2291-316.

25. Raynor BL, et al. Failure of intraoperative monitoring to detect postoperative neurologic deficits: a 25-year experience in 12,375 spinal surgeries. Spine (Phila Pa 1976). 2016;41(17):1387-93.

26. Hsu B, et al. Transcranial motor-evoked potentials combined with response recording through compound muscle action potential as the sole modality of spinal cord monitoring in spinal deformity surgery. Spine (Phila Pa 1976). 2008:33(10):1100-6.

27. Calancie B, et al. "threshold-level" multipulse transcranial electrical stimulation of motor cortex for intraoperative monitoring of spinal motor tracts: description of method and comparison to somatosensory evoked potential monitoring. J Neurosurg. 1998;88(3):457-70.

28. Fercakova A, et al. Graded postischemic reoxygenation reduces lipid peroxidation and reperfusion injury in the rabbit spinal cord. Brain Res. 1992;593(2):159-67.

29. Zhao $\mathrm{M}$, et al. Somatosensory- and motor-evoked potentials in a rabbit model of spinal cord ischemia and reperfusion injury. Spine (Phila Pa 1976). 1997;22(9):1013-7.

30. Hasegawa K, Homma T, Chiba Y. Upper extremity palsy following cervical decompression surgery results from a transient spinal cord lesion. Spine (Phila Pa 1976). 2007:32(6):E197-202.

31. Visser J, et al. Recovery of TES-MEPs during surgical decompression of the spine: a case series of eight patients. J Clin Neurophysiol. 2014:31(6):568-74.

32. Pratheesh R, Babu KS, Rajshekhar V. Improvement in intraoperative transcranial electrical motor-evoked potentials in tethered cord surgery: an analysis of 45 cases. Acta Neurochir. 2014;156(4):723-31.

33. Barley $\mathrm{J}$, et al. Sudden appearance of new upper extremity motor function while performing neurophysiologic intraoperative monitoring during tethered cord release a case report J Pediatr Orthop 2010:30(6):624-8.

34. Voulgaris $\mathrm{S}$, et al. Continuous intraoperative electromyographic and transcranial motor evoked potential recordings in spinal stenosis surgery. Clin Neurosci. 2010;17(2):274-6.

35. Azabou E, et al. Predicting intraoperative feasibility of combined TES-mMEP and CSSEP monitoring during scoliosis surgery based on preoperative neurophysiological assessment. Spine J. 2014;14(7):1214-20.

36. Capone F, et al. The role of motor-evoked potentials in the management of cervical spondylotic myelopathy. Spine J. 2013;13(9):1077-9.

37. Misra UK, Kalita J. Motor evoked potential is useful for monitoring the effect of collar therapy in cervical spondylotic myelopathy. J Neurol Sci. 1998; 154(2):222-8.

38. Kalupahana NS, et al. Abnormal parameters of magnetically evoked motorevoked potentials in patients with cervical spondylotic myelopathy. Spine J. 2008;8(4):645-9.

39. Mochida $K$, et al. A new method of multisegment motor pathway monitoring using muscle potentials after train spinal stimulation. Spine. 1995:20(20):2240-6.

40. Deletis V, Sala F. Intraoperative neurophysiological monitoring of the spinal cord during spinal cord and spine surgery: a review focus on the corticospinal tracts. Clin Neurophysiol. 2008;119(2):248-64. 
41. Machida M, et al. Dissociation of muscle action potentials and spinal somatosensory evoked potentials after ischemic damage of spinal cord. Spine (Phila Pa 1976). 1988;13(10):1119-24.

42. Kitagawa $\mathrm{H}$, et al. Motor evoked-potential monitoring during upper cervicalspine surgery. Spine. 1989;14(10):1078-83.

43. Taylor BA, et al. Temporal summation - the key to motor evoked-potential spinal-cord monitoring in humans. J Neurol Neurosurg Psychiatry. 1993; 56(1):104-6.

44. Malhotra NR, Shaffrey Cl. Intraoperative electrophysiological monitoring in spine surgery. Spine. 2010;35(25):2167-79.

45. Guo $L J$, et al. The correlation between recordable MEPs and motor function during spinal surgery for resection of thoracic spinal cord tumor. J Neurosurg Anesthesiol. 2018;30(1):39-43.

46. Nakanishi K, et al. Electrophysiological evidence of functional improvement in the corticospinal tract after laminoplasty in patients with cervical compressive myelopathy. J Neurosurg Spine. 2014;21(2):210-6.

47. Kanchiku T, et al. Correlation between spinal cord function assessed by intraoperative SCEPs and morphology of the compressed spinal cord on MRI. Clin Spine Surg. 2016;29(10):E496-501.

\section{Publisher's Note}

Springer Nature remains neutral with regard to jurisdictional claims in published maps and institutional affiliations.

Ready to submit your research? Choose BMC and benefit from:

- fast, convenient online submission

- thorough peer review by experienced researchers in your field

- rapid publication on acceptance

- support for research data, including large and complex data types

- gold Open Access which fosters wider collaboration and increased citations

- maximum visibility for your research: over $100 \mathrm{M}$ website views per year

At $\mathrm{BMC}$, research is always in progress.

Learn more biomedcentral.com/submissions 